\title{
The Importance of the Selection of Appropriate Reference Genes for Gene Expression Profiling in Adrenal Medulla or Sympathetic Ganglia of Spontaneously Hypertensive Rat
}

\author{
A. VAVŘíNOVÁ ${ }^{1,2}$, M. BEHULIAK ${ }^{1}$, J. ZICHA $^{1}$ \\ ${ }^{1}$ Department of Experimental Hypertension, Institute of Physiology of the Czech Academy of \\ Sciences, Prague, Czech Republic, ${ }^{2}$ Department of Physiology, Faculty of Science, Charles \\ University in Prague, Prague, Czech Republic
}

Received March 10, 2016

Accepted March 23, 2016

On-line April 12, 2016

\section{Summary}

Catecholaminergic system plays an important role in hypertension development. The available results on mRNA expression of catecholaminergic system genes in spontaneously hypertensive rats (SHR) are often contradictory. One of the possible causes might be the use of various reference genes as internal controls. In the present study, we searched for suitable reference genes in adrenal medulla or sympathetic ganglia of SHR and Wistar-Kyoto (WKY) rats, which would enable reliable comparison of mRNA expression between these two strains. The mRNA expression was measured by quantitative real-time PCR in adrenal medulla and superior cervical ganglia of 4-week-old or 24-week-old SHR and WKY rats. We evaluated 12 reference genes by three software tools (Normfinder, BestKeeper, geNorm) and compared them for the standardization of mRNA expression. Combination of reference genes Hprt1 and Ywhaz in adrenal medulla and Gapdh and 185 in sympathetic ganglia were chosen as the best ones. 185 was found as applicable reference gene in both tissues. We found many alterations in expression of catecholaminergic system genes in adrenal medulla and sympathetic ganglia of SHR. The usage of the most or the least stable reference gene as internal control changed results moderately in sympathetic ganglia but seriously in adrenal medulla. For example, tyrosine hydroxylase (Th) gene was underexpressed in adrenal medulla of adult SHR using the appropriate reference gene but unchanged after the standardization to the least stable reference gene. Our results indicate the importance of appropriate internal control. The suitability of reference genes should be checked again in the case of change in experimental conditions.

\section{Key words}

Adrenal medulla • Gene expression profiling • Reference gene selection • Sympathetic nervous system

\section{Corresponding author}

A. Vavrínová, Institute of Physiology of the Czech Academy of Sciences, Videnska 1083, CZ-142 20 Prague 4, Czech Republic. Fax: +420 24106 2488. E-mail: anna.vavrinova@fgu.cas.cz

\section{Introduction}

Spontaneously hypertensive rats (SHR) represent a widely used experimental model of human essential hypertension. Catecholaminergic system (sympathetic nervous system and adrenal medulla) is involved in high blood pressure development in SHR (Judy and Farrell 1979, Borkowski and Quinn 1983, Lee et al. 1987, Korner et al. 1993). The available information concerning mRNA expression of catecholaminergic system genes in SHR is often contradictory (Friese et al. 2005, Nguyen et al. 2009, Jirout et al. 2010).

For reliable evaluation and reproducibility of mRNA expression of genes of interest by a quantitative real-time PCR (qPCR) according to "The Minimum Information for Publication of Quantitative Real-Time PCR Experiments (MIQE) Guidelines", it is crucial to control and report some parameters as initial sample amount, recovery of RNA isolation, RNA integrity, efficiency of cDNA synthesis, variations in the overall

PHYSIOLOGICAL RESEARCH • ISSN 0862-8408 (print) • ISSN 1802-9973 (online)

(C) 2016 Institute of Physiology of the Czech Academy of Sciences, Prague, Czech Republic

Fax +420 241062 164, e-mail: physres@biomed.cas.cz, www.biomed.cas.cz/physiolres 
transcriptional activity of analyzed samples and normalization used (Bustin et al. 2009). For normalization, the most widely used approach is an internal control gene. The expression of the control gene should not vary in cells or tissues under the experimental conditions (Andersen et al. 2004). There are many commonly used reference genes such as beta-actin (Actb) or glyceraldehyde-3-phosphate dehydrogenase (Gapdh), which could be good as reference gene in some experiments but their expressions are changing under certain conditions (Schmittgen and Zakrajsek 2000). Thus a suitability of gene as the internal control for specific samples and experimental conditions should always be checked carefully.

The aim of this work was to find a suitable reference gene for gene expression profiling in adrenal medulla or sympathetic ganglia of prehypertensive and hypertensive SHR aged 4 and 24 weeks compared to agematched Wistar-Kyoto (WKY) rats. Subsequently, we used the mRNA expression data of genes of catecholaminergic system for demonstration of the importance of reference gene selection.

\section{Methods}

\section{Animals}

All care and experimental protocol, approved by the Ethical Committee of the Institute of Physiology of the Czech Academy of Sciences, comply with European Convention on Animal Protection and Guidelines on Research Animal Use. Experiments were performed in male normotensive Wistar-Kyoto (WKY) and spontaneously hypertensive rats (SHR) aged 4 and 24 weeks, 8 animals being in each group. The rats were housed under standard laboratory conditions (temperature $23 \pm 1{ }^{\circ} \mathrm{C}, 12 \mathrm{~h}$ light-dark cycle, Altromin pellet diet and tap water ad libitum).

\section{Tissue sampling and RNA isolation}

Adrenal medulla and superior cervical ganglia were dissected and carefully cleaned of surrounding tissue. Samples were quickly transferred to $1.5 \mathrm{ml}$ tubes, frozen in liquid nitrogen and stored at $-80{ }^{\circ} \mathrm{C}$ until RNA isolation was undertaken. Total RNA was isolated using Genelute Mammalian Total RNA Miniprep Kit (SigmaAldrich, St Louis, MO, USA). Frozen tissue was immediately transferred to lysis solution with 2-mercaptoethanol (1:100) and homogenized by MagNA Lyser (Roche, Basel, Switzerland) three times for $10 \mathrm{~s}$ at
$7000 \mathrm{rpm}$. Next steps were performed according to the manufacturer's recommendation. The quantity and purity of RNA were checked by spectrophotometer NanoDrop ND 1000 (NanoDrop products, Wilmington, DE, USA). The ratio of absorbance at $260 \mathrm{~nm}$ and $280 \mathrm{~nm}$ was 1.95 on the average. The integrity of randomly selected samples of total RNA was tested using Agilent 2100 Bioanalyzer (Agilent Technologies, Santa Clara, CA), average RNA integrity number (RIN) of tested samples being 7.5. For removal of residual DNA, RNase-Free DNase Set (Qiagen, Hilden, Germany) was used. Absence of DNA contamination was screened by qPCR.

Gene expression profiling - quantitative real-time PCR $(q P C R)$

Gene expression profiling was performed as previously described (Behuliak et al. 2015). $120 \mathrm{ng}$ or $170 \mathrm{ng}$ of total RNA (from adrenal medulla or sympathetic ganglia, respectively) was transcribed to cDNA. Reverse transcription was performed using High Capacity cDNA Reverse Transcription Kit (Life Technologies, Carlsbad, CA, USA) with random primers, proceeded according to manufacturer's instructions. Newly synthesized first-strand cDNA was diluted and aliquots were stored at $-20{ }^{\circ} \mathrm{C}$.

Measurement of gene expression was performed using HOT FIREPol® Probe qPCR Mix Plus (SolisBioDyne, Tartu, Estonia) and TaqMan ${ }^{\circledR}$ Gene Expression Assays (Life Technologies, Carlsbad, CA, USA) on the LightCycler ${ }^{\circledR} 480$ System (Roche, Basel, Switzerland). The list of all used TaqMan ${ }^{\circledR}$ Gene Expression Assays is available in Table 1 which contains full names of genes (gene symbols are used in the text, figures and tables because of their better legibility). Thermocycling conditions were set as recommended for TaqMan ${ }^{\circledR}$ Gene Expression Assays: initial denaturation $\left(95^{\circ} \mathrm{C}\right.$ for $\left.10 \mathrm{~min}\right), 45$ cycles of denaturation $\left(95^{\circ} \mathrm{C}\right.$ for $15 \mathrm{~s}$ ) and annealing/elongation $\left(60^{\circ} \mathrm{C}\right.$ for $\left.1 \mathrm{~min}\right)$. Exported raw data were analyzed by software LinRegPCR (version 2013.0), which set a fluorescence threshold for the determination of the $C_{t}$ value (number of cycles needed to reach the threshold). LinRegPCR was also used for computing of mean PCR efficiency per amplicon (averaged efficiencies of individual samples amplified with particular TaqMan assay) for further analysis (Ruijter et al. 2009). Mean PCR efficiency was used for relative quantification and results were plotted relatively to age-matched WKY controls. 
Table 1. TaqMan $®$ Gene Expression Assays for measurements of expression of reference genes and catecholaminergic system genes.

\begin{tabular}{|c|c|c|c|}
\hline Group of genes & $\begin{array}{l}\text { Gene } \\
\text { symbol }\end{array}$ & Gene name & Assay ID \\
\hline \multirow{12}{*}{ Reference genes } & $A c t b$ & actin, beta & Rn00667869_m1 \\
\hline & $B 2 m$ & beta-2 microglobulin & Rn00560865_m1 \\
\hline & Gapdh & glyceraldehyde-3-phosphate dehydrogenase & Rn01775763_g1 \\
\hline & Gusb & glucuronidase, beta & Rn00566655_m1 \\
\hline & $H m b s$ & hydroxymethylbilane synthase & Rn00565886_m1 \\
\hline & Hprt1 & hypoxanthine phosphoribosyltransferase 1 & Rn01527840_m1 \\
\hline & Ppia & peptidylprolyl isomerase A (cyclophilin A) & Rn00690933_m1 \\
\hline & $R n 18 s$ & $18 \mathrm{~S}$ ribosomal RNA & Rn03928990_g1 \\
\hline & Sdha & succinate dehydrogenase complex, subunit A, flavoprotein (Fp) & Rn00590475_m1 \\
\hline & $T b p$ & TATA box binding protein & Rn01455646_m1 \\
\hline & Tfrc & transferrin receptor & Rn01474701_m1 \\
\hline & Ywhaz & $\begin{array}{l}\text { tyrosine } 3 \text {-monooxygenase/tryptophan 5-monooxygenase } \\
\text { activation protein, zeta }\end{array}$ & Rn00755072_m1 \\
\hline \multirow{6}{*}{$\begin{array}{l}\text { Genes for } \\
\text { catecholamine } \\
\text { biosynthesis }\end{array}$} & $T h$ & tyrosine hydroxylase & Rn00562500_m1 \\
\hline & $D d c$ & DOPA decarboxylase & Rn00561113_m1 \\
\hline & Dbh & dopamine beta-hydroxylase & Rn00565819_m1 \\
\hline & Pnmt & phenylethanolamine-N-methyltransferase & Rn01495588_m1 \\
\hline & $Q d p r$ & quinoid dihydropteridine reductase & Rn00574367_m1 \\
\hline & Gch1 & GTP cyclohydrolase 1 & Rn00577450_m1 \\
\hline \multirow{6}{*}{$\begin{array}{l}\text { Genes related to } \\
\text { catecholamine } \\
\text { vesicles }\end{array}$} & Slcl8a1 & solute carrier family 18, member A1 (alias Vmat1) & Rn00461866_m1 \\
\hline & Slcl8a2 & solute carrier family 18, member A2 (alias Vmat2) & Rn00564688_m1 \\
\hline & Chga & chromogranin A & Rn00572200_m1 \\
\hline & Chgb & chromogranin B & Rn01514853_m1 \\
\hline & Scg2 & secretogranin II & Rn02042961_s1 \\
\hline & Npy & neuropeptide Y & Rn01410145_m1 \\
\hline \multirow{4}{*}{$\begin{array}{l}\text { Genes for } \\
\text { catecholamine } \\
\text { reuptake or } \\
\text { degradation }\end{array}$} & Slc $6 a 2$ & solute carrier family 6, member 2 (alias Net) & Rn00580207_m1 \\
\hline & Comt & catechol-O-methyltransferase & Rn00561037_m1 \\
\hline & Maoa & monoamine oxidase A & Rn01430950_m1 \\
\hline & Maob & monoamine oxidase B & Rn00566203_m1 \\
\hline
\end{tabular}

\section{Selection of reference genes}

We analyzed mRNA expression of 12 reference genes the most used in the literature. The recommended number of reference genes for reliable analysis is 5-10 (Andersen et al. 2004). The reference genes (Table 1) were chosen with emphasis on their different biological function (e.g. Actb gene encodes cytoskeletal protein, $B 2 m$ gene encodes component of MHC class I complex, Gapdh gene encodes glycolytic enzyme etc.) for two reasons. Firstly, the involvement of tested reference genes in various pathways reduce the possibility that the genes could be coregulated what might affect the process of 
selection (Andersen et al. 2004). Secondly, different biological function of tested genes increase the chance to find appropriate reference gene whose mRNA expression is unaltered by certain experimental conditions, e.g. it is not surprising that Gapdh is not appropriate reference gene for research of the ischemia and, on the contrary, the expression of genes encoding proteins involved in DNA synthesis/transcription is much more stable under the conditions of ischemia (Vesentini et al. 2012).

To enable the comparison of gene expression between prehypertensive and hypertensive rats and to respect the fact that the expression of some genes used as internal controls can change during the development (Robert et al. 2002), we tested the stability of the expression of reference genes in particular tissue for both ages together. The reference genes appropriate for developmental study (stable in overall rankings) are also useful for the standardization of expression within a particular age.

Table 2. Comparison of gene expression stability of reference genes in adrenal medulla according to software tools Normfinder, geNorm and BestKeeper.

\begin{tabular}{|c|c|c|c|c|c|c|}
\hline \multirow{2}{*}{ Gene } & \multirow{2}{*}{$\begin{array}{l}\text { Mean PCR } \\
\text { efficiency }\end{array}$} & \multicolumn{2}{|c|}{$\begin{array}{c}\text { Normfinder } \\
\text { Stability value }\end{array}$} & \multicolumn{2}{|c|}{$\begin{array}{c}\text { geNorm } \\
\text { Expression stability M }\end{array}$} & \multirow{2}{*}{$\begin{array}{c}\text { BestKeeper } \\
\text { Correlation coef. } \\
\begin{array}{c}\text { No efficiency } \\
\text { correction }\end{array}\end{array}$} \\
\hline & & $\begin{array}{c}\text { No efficiency } \\
\text { correction }\end{array}$ & $\begin{array}{r}\text { Efficiency } \\
\text { corrected }\end{array}$ & $\begin{array}{l}\text { No efficiency } \\
\text { correction }\end{array}$ & $\begin{array}{l}\text { Efficiency } \\
\text { corrected }\end{array}$ & \\
\hline$A c t b$ & $1.748 \pm 0.013$ & 0.120 & 0.127 & 0.350 & 0.322 & 0.967 \\
\hline$B 2 m$ & $1.923 \pm 0.010$ & $\underline{0.240}$ & $\underline{0.217}$ & $\underline{0.468}$ & $\underline{0.425}$ & $\underline{0.943}$ \\
\hline Gapdh & $1.805 \pm 0.011$ & 0.132 & 0.127 & 0.362 & 0.328 & 0.978 \\
\hline Gusb & $1.843 \pm 0.011$ & $\underline{0.236}$ & $\underline{0.211}$ & $\underline{0.445}$ & $\underline{0.398}$ & $\underline{0.943}$ \\
\hline Hmbs & $1.894 \pm 0.013$ & 0.116 & 0.098 & 0.350 & 0.311 & 0.977 \\
\hline Hprt1 & $2.021 \pm 0.027$ & 0.135 & 0.123 & 0.384 & 0.357 & 0.951 \\
\hline Ppia & $1.843 \pm 0.023$ & 0.132 & 0.120 & 0.368 & 0.327 & 0.976 \\
\hline$R n 18 s$ & $1.933 \pm 0.003$ & 0.086 & 0.075 & 0.348 & 0.305 & 0.982 \\
\hline Sdha & $1.883 \pm 0.009$ & 0.151 & 0.134 & 0.382 & 0.341 & 0.972 \\
\hline$T b p$ & $1.790 \pm 0.008$ & 0.138 & 0.095 & 0.410 & 0.333 & 0.971 \\
\hline Tfrc & $1.830 \pm 0.013$ & $\underline{0.573}$ & $\underline{0.495}$ & $\underline{1.033}$ & $\underline{0.890}$ & $\underline{0.823}$ \\
\hline Ywhaz & $1.878 \pm 0.019$ & 0.105 & 0.102 & 0.360 & 0.326 & 0.985 \\
\hline
\end{tabular}

Data were used in efficiency corrected or non-corrected form. Mean PCR efficiency was computed for all samples from both tissues and ages. Three most stable reference genes (with the lowest stability value) according to particular software tool are in bold whereas three least stable ones (with the highest stability value) are underlined. The gene symbols are used for better legibility, the full names of genes are given in Table 1.

Computing of the expression stability of reference genes was done by Normfinder (Andersen et al. 2004), geNorm (Vandesompele et al. 2002) and BestKeeper (Pfaffl et al. 2004) software tools. Input expression data were non-corrected (mean PCR efficiency was considered being equal 2) or corrected according to mean PCR efficiency (only in Normfinder and geNorm) (De Spiegelaere et al. 2015). The reference genes were ranked according to the obtained stability values for each tissue (the lower stability value means the better reference gene). The rankings of reference genes obtained by Normfinder, geNorm and BestKeeper were compared. For further analysis, we decided to use the results from Normfinder for three reasons. Firstly, this software uses model-based approach for gene rankings which is less sensitive to coregulation of tested genes than pairwise comparison approach (Andersen et al. 2004). Secondly, Normfinder enables efficiency correction. Finally, Normfinder allows to choose the best combination of two reference genes which improves stability of expression even more. Normalization to the best combination of two reference genes and by the least 
stable gene was used for the demonstration of importance of careful selection of appropriate reference gene.

Statistics

Data are expressed as mean \pm SD. Normality of distribution was tested by Shapiro-Wilk test. Due to the failure of normality in many cases, all data were analyzed by non-parametric Kruskal-Wallis and post-hoc Dunn's test. The differences were considered to be significant at $\mathrm{p}<0.01$ level.

Table 3. Comparison of gene expression stability of reference genes in sympathetic ganglia according to software tools Normfinder, geNorm and BestKeeper.

\begin{tabular}{lcccccc}
\hline \multirow{2}{*}{ Gene } & $\begin{array}{c}\text { Mean PCR } \\
\text { efficiency }\end{array}$ & \multicolumn{2}{c}{$\begin{array}{c}\text { Normfinder } \\
\text { Stability value }\end{array}$} & $\begin{array}{c}\text { geNorm } \\
\text { Expression stability M }\end{array}$ & $\begin{array}{c}\text { BestKeeper } \\
\text { Correlation coef. }\end{array}$ \\
\cline { 3 - 7 } & & $\begin{array}{c}\text { No efficiency } \\
\text { correction }\end{array}$ & $\begin{array}{c}\text { Efficiency } \\
\text { corrected }\end{array}$ & $\begin{array}{c}\text { No efficiency } \\
\text { correction }\end{array}$ & $\begin{array}{c}\text { Efficiency } \\
\text { corrected }\end{array}$ & $\begin{array}{c}\text { No efficiency } \\
\text { correction }\end{array}$ \\
\hline Actb & $1.748 \pm 0.013$ & $\mathbf{0 . 0 6 7}$ & $\mathbf{0 . 0 5 3}$ & $\mathbf{0 . 2 1 5}$ & $\mathbf{0 . 1 8 8}$ & $\mathbf{0 . 9 0 9}$ \\
B2m & $1.923 \pm 0.010$ & $\underline{0.140}$ & $\underline{0.129}$ & $\underline{0.341}$ & $\underline{0.316}$ & $\underline{0.680}$ \\
Gapdh & $1.805 \pm 0.011$ & $\mathbf{0 . 0 5 3}$ & $\mathbf{0 . 0 4 5}$ & $\mathbf{0 . 2 1 4}$ & $\mathbf{0 . 1 8 9}$ & $\mathbf{0 . 7 4 3}$ \\
Gusb & $1.843 \pm 0.011$ & 0.100 & 0.089 & 0.274 & 0.244 & 0.725 \\
Hmbs & $1.894 \pm 0.013$ & 0.086 & 0.080 & 0.247 & 0.224 & 0.756 \\
Hprt1 & $2.021 \pm 0.027$ & 0.095 & $\underline{0.093}$ & 0.275 & $\underline{0.262}$ & $\underline{0.448}$ \\
Ppia & $1.843 \pm 0.023$ & $\underline{0.111}$ & $\underline{0.100}$ & $\underline{0.297}$ & $\underline{0.264}$ & 0.788 \\
Rn18s & $1.933 \pm 0.003$ & 0.070 & 0.064 & 0.244 & 0.219 & 0.498 \\
Sdha & $1.883 \pm 0.009$ & $\mathbf{0 . 0 6 1}$ & $\mathbf{0 . 0 5 5}$ & $\mathbf{0 . 2 2 7}$ & $\mathbf{0 . 2 0 4}$ & $\mathbf{0 . 8 4 4}$ \\
Tbp & $1.790 \pm 0.008$ & $\underline{0.104}$ & 0.089 & $\underline{0.286}$ & 0.245 & 0.826 \\
Tfrc & $1.830 \pm 0.013$ & 0.095 & 0.084 & 0.282 & 0.249 & 0.810 \\
Ywhaz & $1.878 \pm 0.019$ & 0.071 & 0.066 & 0.230 & 0.209 & 0.818 \\
\hline
\end{tabular}

Data were used in efficiency corrected or non-corrected form. Mean PCR efficiency was computed for all samples from both tissues and ages. Three most stable reference genes (with the lowest stability value) according to particular software tool are in bold whereas three least stable ones (with the highest stability value) are underlined. The gene symbols are used for better legibility, the full names of genes are given in Table 1.

\section{Results}

\section{Selection of reference genes}

In order to identify the most stable reference gene, we examined 12 reference genes in adrenal medulla and sympathetic ganglia using the software tools Normfinder, geNorm and BestKeeper (Tables 2 and 3). We arranged the genes according to their stability values (the lower stability value means the better reference gene). Efficiency correction changed our rankings, particularly the position of genes with low PCR efficiency. We obtained very similar rankings from Normfinder and geNorm, the most and the least stable genes were the same using both methods. The ranking obtained by Bestkeeper was more different, especially in sympathetic ganglia, where the expression stability of reference genes was similar. For further analysis, we decided to use the ranking from Normfinder.

In adrenal medulla (Fig. 1A), the most stable reference gene was $18 S$ with the stability value 0.075 . The pair Hprtl and Ywhaz was chosen as the best combination of two reference genes with stability value 0.047. The least stable reference gene was Tfrc with stability value 0.495 . In sympathetic ganglia (Fig. 1B), the most stable gene was Gapdh with the stability value 0.045 . The pair $18 S$ and Gapdh was chosen as the best combination of two reference genes with stability value 0.037. The least stable reference gene in sympathetic ganglia was $B 2 m$ with stability value 0.129 . $18 S$ can be used as a common reference gene for both catecholaminergic tissues (stability value 0.075 in adrenal medulla and 0.064 in sympathetic ganglia). 

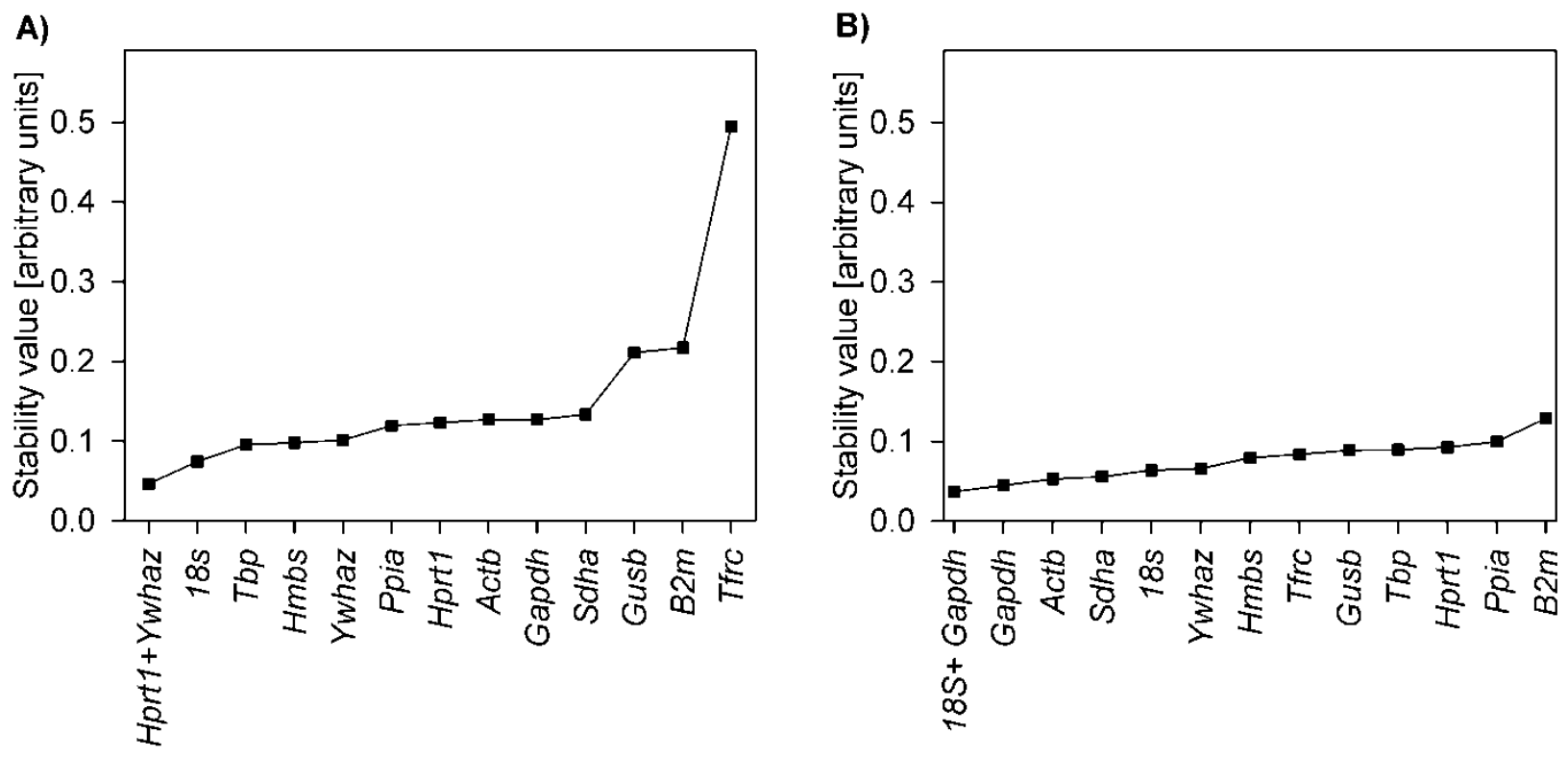

Fig. 1. Stability values of reference genes in adrenal medulla (A) and sympathetic ganglia (B) of spontaneously hypertensive and Wistar-Kyoto rats aged 4 and 24 weeks computed by software Normfinder. Input data were adjusted according to PCR efficiency of particular gene. The reference genes were ranked according to the obtained stability values for each tissue (the lower stability value means the better reference gene). The gene symbols are used for better legibility, the full names of genes are given in Table 1.

Comparison of standardization to various reference genes

To determine the impact of selection of proper reference gene, we performed standardization of mRNA expression of catecholaminergic system genes to all reference genes. For illustrative purposes we show the best combination of reference genes in comparison with the least stable reference gene. When comparing the standardization of mRNA expression in adrenal medulla with either the best combination of reference genes (Hprt1 and Ywhaz, Fig. 2A) or with the least stable Tfrc (Fig. 2B), 16 significant differences between SHR and WKY rats appeared or disappeared. For example, tyrosine hydroxylase (Th) gene was underexpressed in adrenal medulla of adult SHR using Hprt1 and Ywhaz as the reference gene, but there was no significant change after the standardization to Tfrc. On the contrary, there was no difference in catechol-O-methyltransferase (Comt) gene expression, but the expression seemed to be decreased in young SHR using Tfrc as reference gene. One of the problems with Tfrc as reference gene in adrenal medulla is its significantly increased expression in young SHR compared to WKY (mean $C_{t}$ SHR $32.7 \pm 1.2$ vs. WKY $34.0 \pm 0.6$ ), which leads to underestimation of the expression in SHR. The expression of Tfrc in adult SHR and WKY rats does not differ significantly because of high standard deviation (mean $\mathrm{C}_{\mathrm{t}}$ SHR $34.4 \pm 1.9$ vs. WKY $33.8 \pm 0.4$ ), but results were also affected during standardization.

We also compared standardization of mRNA expression in sympathetic ganglia to either the best combination of reference genes (18S and Gapdh, Fig. 3A) or with the least stable $B 2 m$ (Fig. 3B), only four significant differences between investigated groups appeared or disappeared. For example, Th was overexpressed in adult SHR using $18 S$ and Gapdh as a reference gene, but there was no change after standardization to $B 2 \mathrm{~m}$. On the contrary, there was no difference in chromogranin A (Chga) gene expression, but the expression seemed to be decreased in adult SHR using $B 2 m$ as reference gene. $B 2 m$ expression does not differ between SHR and WKY rats aged 4 weeks (mean $\mathrm{C}_{\mathrm{t}}$ SHR $23.9 \pm 0.3$ vs. WKY $23.7 \pm 0.5$ ) and 24 weeks (mean $\mathrm{C}_{\mathrm{t}}$ SHR $23.3 \pm 0.2$ vs. WKY 23.4 \pm 0.3 ). However, standardization to $B 2 m$ still caused aforementioned changes in results, although the impact of using the least stable reference gene was only moderate in sympathetic ganglia in comparison to adrenal medulla. 


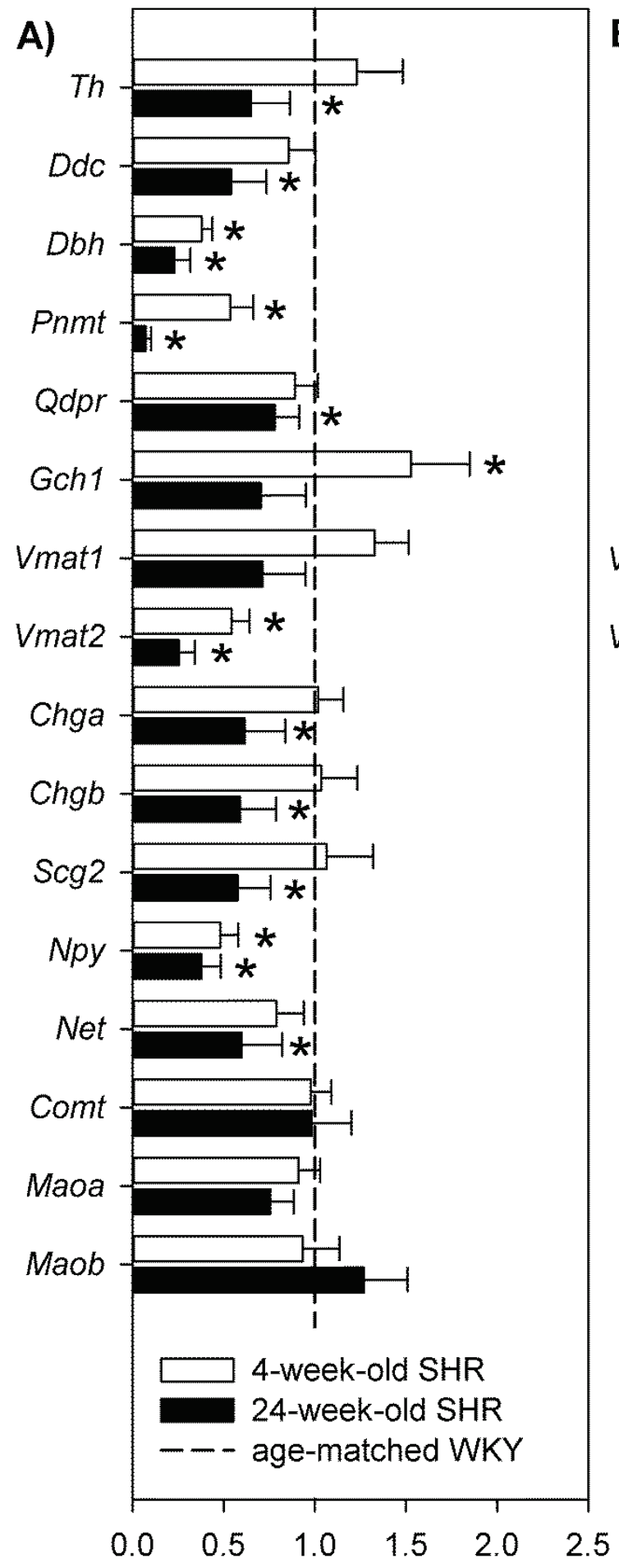

Relative mRNA expression [arbitrary units]

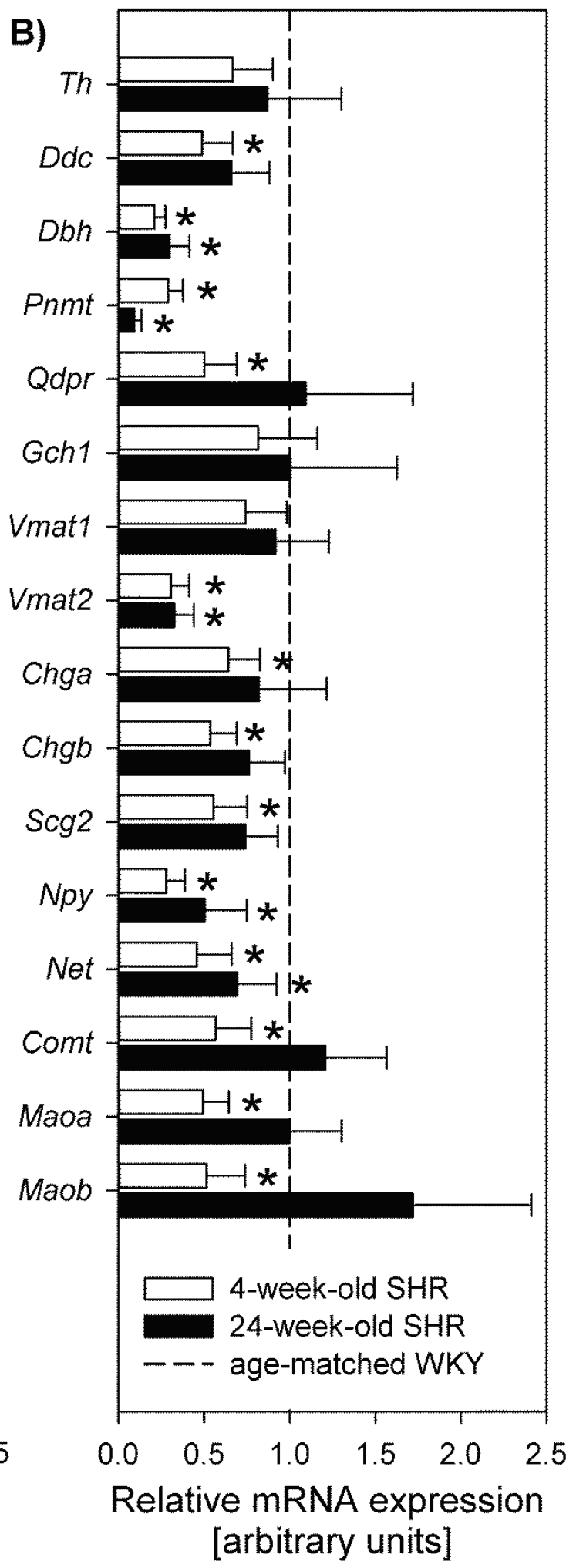

Fig. 2. Gene expression profiling of genes of catecholaminergic system in adrenal medulla of spontaneously hypertensive (SHR) and Wistar-Kyoto (WKY) rats aged 4 and 24 weeks. Data were standardized to the best combination of reference genes Hprt $1+Y w h a z(\mathbf{A})$ or to the least stable reference gene $\operatorname{Tfr}(\mathbf{B})$. Data are plotted relatively to age-matched WKY and as means $\pm S D$, $n=8$ in each group. $* p<0.01$ vs. age-matched WKY. The gene symbols are used for better legibility, the full names of genes are given in Table 1. 
A)
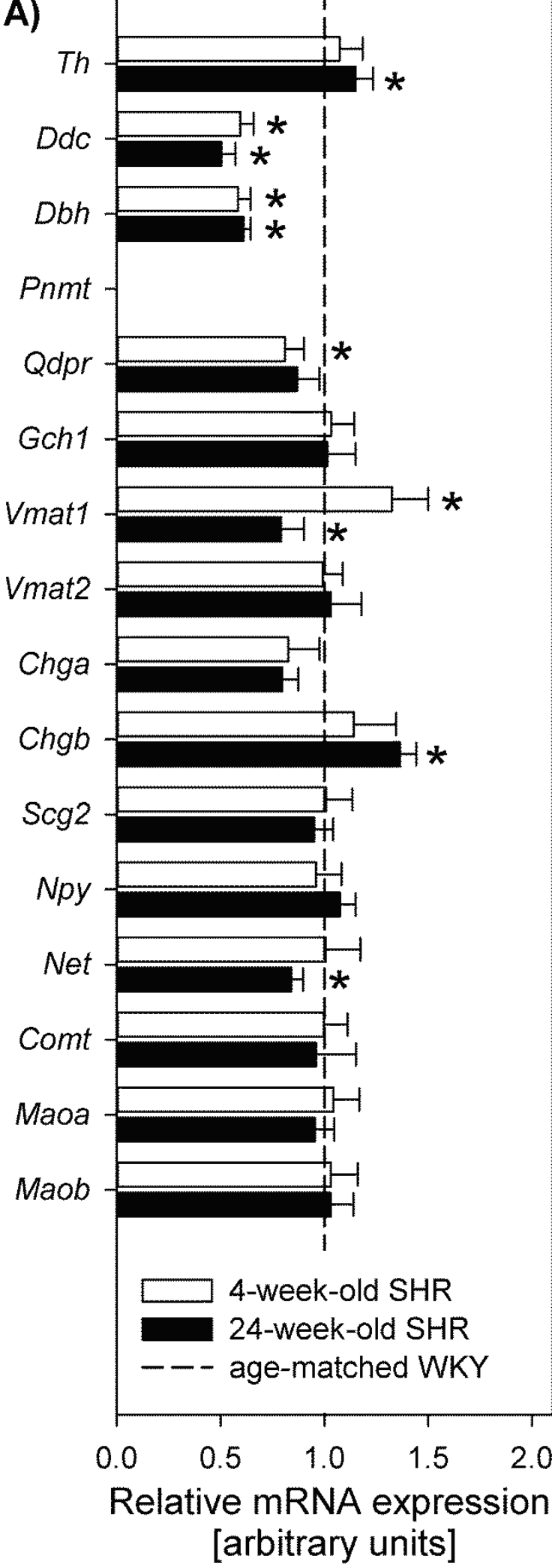

B)

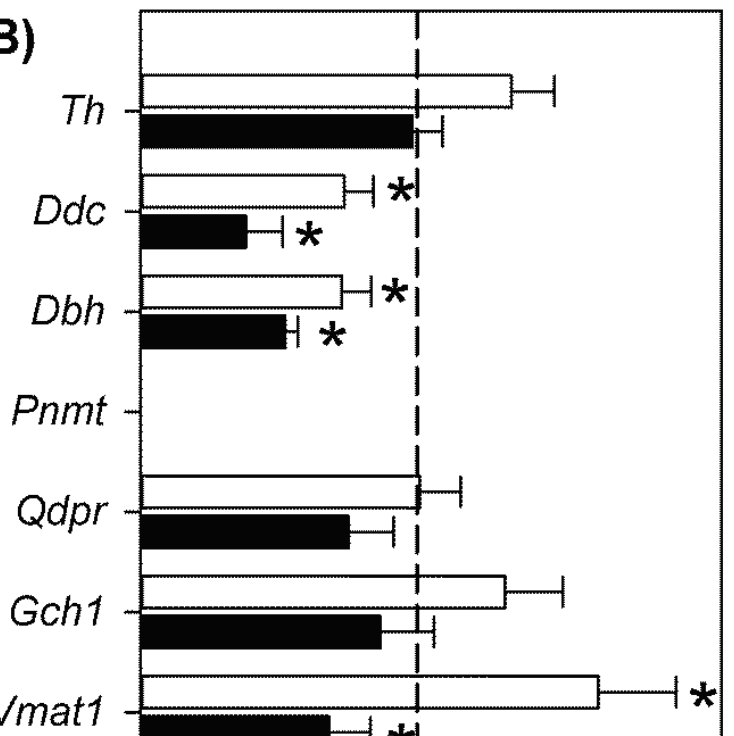

Vmat2

Chga

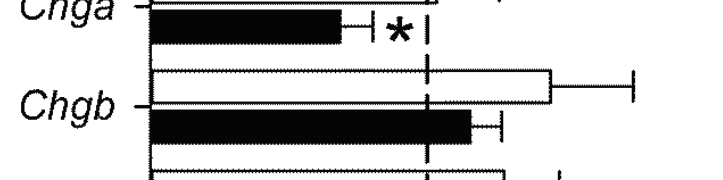

$\operatorname{Scg} 2$

Npy

Net

Comt

Maoa

Maob
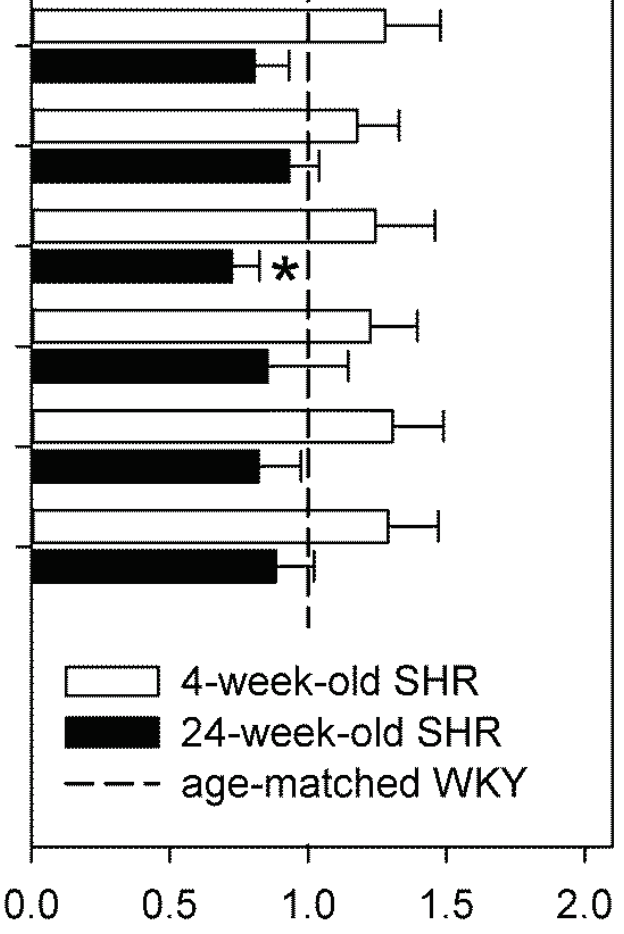

Relative mRNA expression [arbitrary units]

Fig. 3. Gene expression profiling of genes of catecholaminergic system in sympathetic ganglia of spontaneously hypertensive (SHR) and Wistar-Kyoto (WKY) rats aged 4 and 24 weeks. Data were standardized to the best combination of reference genes $18 S+$ Gapdh $(\mathbf{A})$ or to the least stable reference gene $B 2 m(B)$. Data are plotted relatively to age-matched WKY and as means $\pm S D, n=8$ in each group. $* p<0.01$ vs. age-matched WKY. The gene symbols are used for better legibility, the full names of genes are given in Table 1. 


\section{Discussion}

In the present study, we compared various reference genes for gene expression profiling in adrenal medulla and sympathetic ganglia of spontaneously hypertensive (SHR) and Wistar-Kyoto (WKY) rats. According to available literature, this is for the first time when a comparison of various reference genes in adrenal medulla and sympathetic ganglia of rats was performed, although there is a study of Zhou et al. (2010) on neuronal differentiation of PC12 cells (a cell line derived from pheochromocytoma of rat adrenal medulla), where ribosomal protein genes Rpl19 and Rpl29 but not Gapdh were recommended as reference genes for gene expression profiling.

Samples originating from SHR aged 4 or 24 weeks (prehypertensive and hypertensive) and from age-matched WKY were compared. Reference genes were selected with the emphasis on their different biological function to reduce the chance that these genes could be regulated in the same manner. Efficiency correction changed the position of the genes with low PCR efficiency so that this important parameter should be taken into consideration for reference gene validation (De Spiegelaere et al. 2015). Rankings of reference genes by software tools Normfinder and geNorm were similar, both tools determined the same most and least stable reference genes.

When we compare our rankings of reference genes from adrenal medulla and sympathetic ganglia, we can see that the range of stability values in sympathetic ganglia is narrow (Fig. 1B), while it is wide in adrenal medulla (Fig. 1A). What does it mean for our data? Is the least stable gene for adrenal medulla Tfrc much worse reference gene than $B 2 m$ for sympathetic ganglia? We showed that using the least stable reference gene $B 2 m$ as internal control in sympathetic ganglia influenced results moderately (appearance or disappearance of 4 significant differences between investigated groups). In sympathetic ganglia, it is not possible to separate the recommended reference genes from the genes unsuitable as internal controls. On the contrary, using Tfrc in adrenal medulla influenced results seriously (appearance or disappearance of 16 significant differences between investigated groups) in comparison to the most stable combination of reference genes in each tissue. In adrenal medulla, the choice of reference gene is much more important, at least, the usage of the three least stable genes Gusb, B2m and Tfrc cannot be recommended.
As sympathetic ganglia and adrenal medulla are tissues of related neural origin, the suitability of particular reference gene could be similar in both of them. However, among the first five most stable genes only two of them (18S and Ywhaz) are the same for both sympathetic ganglia and adrenal medulla (Fig. 1A and Fig. 1B). In fact, $18 S$ was often used as a reference gene for adrenal medulla but without reasoning of its selection (Friese et al. 2005, Jirout et al. 2010). On the other hand, Tfrc seems to be a quite good reference gene in sympathetic ganglia, while it is the least stable gene in adrenal medulla. Furthermore, Ppia used as internal control for adrenal medulla (O'Connor et al. 1999, Nguyen et al. 2009) and situated in the middle of our ranking of reference genes for this tissue is the second least stable gene in sympathetic ganglia. Thus, we cannot extrapolate our knowledge about appropriate reference genes from one tissue to another even if they are closely related.

In the present study, we evaluated the suitability of reference genes in adrenal medulla and sympathetic ganglia of SHR and WKY rats examined in two ages. After all, we selected the best combination of reference genes for developmental study in adrenal medulla (Hprt1 and Ywhaz) and sympathetic ganglia (18S and Gapdh) of SHR and WKY rats. $18 S$ is also usable for standardization of gene expression profiling in both catecholaminergic tissues if there is a need for a common reference gene in both catecholaminergic tissues. However, it is necessary to realize that our ranking of reference genes is valid only for intact rats. The suitability of reference genes should be checked again in the case of certain changes in experimental conditions such as exposure of animals to stress, hypoxia or pharmacological interventions. It is possible to make this subsequent reference gene selection easier by excluding some reference genes from the process. Firstly, it is possible to exclude reference genes which are not appropriate for standardization of expression in intact animals. Secondly, it is possible to suppose that the expression of certain reference genes might change under the experimental conditions (e.g. Gapdh expression under the conditions of ischemia). But for a reliable analysis, it is still necessary to analyze at least five reference genes (Andersen et al. 2004) and it is not possible to predict for sure, the expression of which gene will not change under the experimental conditions. According to our recent unpublished results, $18 S$ is not appropriate for standardization in adrenal medullas from intact and 
stressed adult SHR, although its expression is not significantly different (mean $\mathrm{C}_{\mathrm{t}}$ SHR $9.0 \pm 0.2$ vs. SHR stressed $8.8 \pm 0.1$ ). The use of $18 S$ for standardization in this experiment would again lead to incorrect results (e.g. decreasing expression of DOPA decarboxylase $(D d c)$ during stress, while expression is unchanged after a correct standardization).

In conclusion, the selection of reference gene is a very important step in gene expression profiling by quantitative real-time PCR and thus the choice of internal control can affect the results seriously. We selected the best combination of reference genes for gene expression profiling in adrenal medulla (Hprt1 and Ywhaz) and sympathetic ganglia (18S and Gapdh) of SHR and WKY rats. As a common reference gene for both catecholaminergic tissues $18 S$ can be used. The suitability of reference genes should be checked again in the case of change in experimental conditions.

\section{Conflict of Interest}

There is no conflict of interest.

\section{Acknowledgements}

This work was supported by institutional support RVO: 67985823 and by research grants GACR 14-16225P (both Czech Science Foundation) and GAUK 966214 (Charles University Grant Agency).

\section{References}

ANDERSEN CL, JENSEN JL, ØRNTOFT TF: Normalization of real-time quantitative reverse transcription-PCR data: a model-based variance estimation approach to identify genes suited for normalization, applied to bladder and colon cancer data sets. Cancer Res 64: 5245-5250, 2004.

BEHULIAK M, VAVŘíNOVÁ A, BENCZE M, POLGÁROVÁ K, ERGANG P, KUNEŠ J, VANĚČKOVÁ I, ZICHA $\mathrm{J}$ : Ontogenetic changes in contribution of calcium sensitization and calcium entry to blood pressure maintenance of Wistar-Kyoto and spontaneously hypertensive rats. J Hypertens 33: 2443-2454, 2015.

BORKOWSKI KR, QUINN P: The effect of bilateral adrenal demedullation on vascular reactivity and blood pressure in spontaneously hypertensive rats. Br J Pharmacol 80: 429-437, 1983.

BUSTIN SA, BENES V, GARSON JA, HELLEMANS J, HUGGETT J, KUBISTA M, MUELLER R, NOLAN T, PFAFFL MW, SHIPLEY GL, VANDESOMPELE J, WITTWER CT: The MIQE guidelines: minimum information for publication of quantitative real-time PCR experiments. Clin Chem 55: 611-622, 2009.

DE SPIEGELAERE W, DERN-WIELOCH J, WEIGEL R, SCHUMACHER V, SCHORLE H, NETTERSHEIM D, BERGMANN M, BREHM R, KLIESCH S, VANDEKERCKHOVE L, FINK C: Reference gene validation for RT-qPCR, a note on different available software packages. PLoS One 10: e0122515, 2015.

FRIESE RS, MAHBOUBI P, MAHAPATRA NR, MAHATA SK, SCHORK NJ, SCHMID-SCHÖNBEIN GW, O'CONNOR DT: Common genetic mechanisms of blood pressure elevation in two independent rodent models of human essential hypertension. Am J Hypertens 18: 633-652, 2005.

JIROUT ML, FRIESE RS, MAHAPATRA NR, MAHATA M, TAUPENOT L, MAHATA SK, KREN V, ZÍDEK V, FISCHER J, MAATZ H, ZIEGLER MG, PRAVENEC M, HUBNER N, AITMAN TJ, SCHORK NJ, O'CONNOR DT: Genetic regulation of catecholamine synthesis, storage and secretion in the spontaneously hypertensive rat. Hum Mol Genet 19: 2567-2580, 2010.

JUDY WV, FARRELL SK: Arterial baroreceptor reflex control of sympathetic nerve activity in the spontaneously hypertensive rat. Hypertension 1: 605-614, 1979.

KORNER P, BOBIK A, ODDIE C, FRIBERG P: Sympathoadrenal system is critical for structural changes in genetic hypertension. Hypertension 22: 243-252, 1993.

LEE RM, TRIGGLE CR, CHEUNG DW, COUGHLIN MD: Structural and functional consequence of neonatal sympathectomy on the blood vessels of spontaneously hypertensive rats. Hypertension 10: 328-338, 1987.

NGUYEN P, PELTSCH H, DE WIT J, CRISPO J, UBRIACO G, EIBL J, TAI TC: Regulation of the phenylethanolamine N-methyltransferase gene in the adrenal gland of the spontaneous hypertensive rat. Neurosci Lett 461: 280-284, 2009. 
O'CONNOR DT, TAKIYYUDDIN MA, PRINTZ MP, DINH TQ, BARBOSA JA, ROZANSKY DJ, MAHATA SK, WU H, KENNEDY BP, ZIEGLER MG, WRIGHT FA, SCHLAGER G, PARMER RJ: Catecholamine storage vesicle protein expression in genetic hypertension. Blood Press 8: 285-295, 1999.

PFAFFL MW, TICHOPAD A, PRGOMET C, NEUVIANS TP: Determination of stable housekeeping genes, differentially regulated target genes and sample integrity: BestKeeper--Excel-based tool using pair-wise correlations. Biotechnol Lett 26: 509-515, 2004.

ROBERT C, MCGRAW S, MASSICOTTE L, PRAVETONI M, GANDOLFI F, SIRARD MA: Quantification of housekeeping transcript levels during the development of bovine preimplantation embryos. Biol Reprod 67: 1465-1472, 2002.

RUIJTER JM, RAMAKERS C, HOOGAARS WM, KARLEN Y, BAKKER O, VAN DEN HOFF MJ, MOORMAN AF: Amplification efficiency: linking baseline and bias in the analysis of quantitative PCR data. Nucleic Acids Res 37: e45, 2009.

SCHMITTGEN TD, ZAKRAJSEK BA: Effect of experimental treatment on housekeeping gene expression: validation by real-time, quantitative RT-PCR. J Biochem Biophys Methods 46: 69-81, 2000.

VANDESOMPELE J, DE PRETER K, PATTYN F, POPPE B, VAN ROY N, DE PAEPE A, SPELEMAN F: Accurate normalization of real-time quantitative RT-PCR data by geometric averaging of multiple internal control genes. Genome Biol 3: RESEARCH0034, 2002.

VESENTINI N, BARSANTI C, MARTINO A, KUSMIC C, RIPOLI A, ROSSI A, L'ABBATE A: Selection of reference genes in different myocardial regions of an in vivo ischemia/reperfusion rat model for normalization of antioxidant gene expression. BMC Res Notes 5: 124, 2012.

ZHOU L, LIM QE, WAN G, TOO HP: Normalization with genes encoding ribosomal proteins but not GAPDH provides an accurate quantification of gene expressions in neuronal differentiation of PC12 cells. BMC Genomics 11: 75, 2010. 